\title{
Comparison of the Effects of Retinoic Acid and Nerve Growth Factor on PC12 Cell Proliferation, Differentiation, and Gene Expression
}

\author{
Jose Miguel Cosgaya, Pilar Garcia-Villalba, Rosario Perona, and Ana Aranda \\ Instituto de Investigaciones Biomédicas, Consejo Superior de Investigaciones Científicas, Madrid, Spain
}

\begin{abstract}
Retinoic acid (RA) produced a dose-dependent inhibition of PC12 cell growth and the appearance of cell clusters without neurite extension. RA-induced cell clumping was similar to that caused by dexamethasone (Dx). Nerve growth factor (NGF) induced neurite extension, and the combination of RA plus NGF produced a maximal decrease in cell proliferation with a mixed morphology in which part of the cell population had neurites and part formed clumps. Transcriptional effects of RA were demonstrated by the increase in the activity of reporter constructs that contain an RA response element. $\mathrm{RA}$ also regulated expression of endogenous genes in PC12 cells. The retinoid produced a two- to threefold increase in level of p75 ${ }^{\text {LNGFR }}$ mRNA (the low-affinity NGF receptor), without altering expression of the trk protooncogene (the high-affinity NGF receptor carrying tyrosine kinase activity). RA also caused a transient increase in level of tyrosine hydroxylase (TH) mRNA (twofold after $16 \mathrm{~h}$ ), which returned to basal levels and then decreased relative to basal levels at $48 \mathrm{~h}$. The effect of NGF on the expression of these genes was identical to that produced by RA. However, incubation with $\mathrm{Dx}$ did not induce p75 LNGFR mRNA and produced a strong and sustained increase of TH mRNA level (three- to fivefold after $48 \mathrm{~h}$ ). These results show that, despite the common morphological changes produced by RA and glucocorticoids in PC12 cells, the biochemical changes caused by RA are similar to those produced by NGF. Therefore, RA could initiate a biochemical program of neuronal differentiation in PC12 cells, although a fully differentiated phenotype with neurite extension is not obtained. Key Words: PC12 cells-Retinoic acid-Nuclear receptors-Tyrosine hydroxylase - $\mathrm{p} 75^{\mathrm{LNGFR}}$ - trk - Sympathoadrenal lineage. J. Neurochem. 66, 89-98 (1996).
\end{abstract}

PC12 cells, derived from a rat pheochromocytoma (Greene and Tischler, 1976), are a useful model to study cell differentiation. This cell line has characteristics of precursor cells for both sympathetic neurons and chromaffin cells. Glucocorticoid hormones promote differentiation of PC12 cells along the chromaffin pathway. Treatment with glucocorticoids induces transcription of tyrosine hydroxylase (TH) and other chro- maffin markers as well as morphological changes characterized by cell rounding and formation of cell clusters (Greene and Tischler, 1982; Lewis et al., 1983). However, on incubation with neurotrophic factors PC12 cells acquire a neuronal phenotype. Nerve growth factor (NGF) is the best-characterized neurotrophic factor (for review, see Levi-Montalcini, 1987). Ligand activation of the NGF receptor tyrosine kinase, the trk protooncogene (Kaplan et al., 1991; Klein et al., 1991), leads to biochemical and morphological changes characteristic of sympathetic neuronal differentiation, including neurite extension, cessation of cell division, and expression of neuronal-specific genes (for review, see Halegoua et al., 1991). A low-affinity receptor for NGF, p75 ${ }^{\text {LNGFR }}$, which may also play a role in the signal transduction pathway of the factor, is also expressed at high levels in PC12 cells (Radeke et al., 1987). In these cells, fibroblast growth factor also triggers growth arrest and neurite outgrowth (Togari et al., 1983).

Retinoic acid (RA), an endogenous metabolite of vitamin $A$, is a potent regulator of growth and differentiation of different types of cultured cells. The actions of RA are mediated by nuclear receptors (RARs and RXRs), which belong to the steroid/thyroid hormone receptors superfamily and act as ligand-inducible transcription factors (for a recent review, see Guiguère, 1994). RA receptors, which show the highest homology with the thyroid hormone and vitamin D3 receptors, are expressed in neural tissues, and there is increasing evidence that RA can play an important role in

Received June 7, 1995; revised manuscript received August 1, 1995; accepted August 1, 1995.

Address correspondence and reprint requests to Dr. A. Aranda at Instituto de Investigaciones Biomédicas, Consejo Superior de Investigaciones Científicas, Arturo Duperier 4, 28029-Madrid, Spain.

Abbreviations used: bFGF, basic fibroblast growth factor; CAT, chloramphenicol acetyltransferase; DR, direct repeat; Dx, dexamethasone; EGF, epidermal growth factor; IGF-1, insulin-like growth factor; MMTV-LTR, mouse mammary tumor virus-long terminal repeat; NGF, nerve growth factor; RA, retinoic acid; T3, triiodothyronine; TH, tyrosine hydroxylase; TR, thyroid hormone receptor; VD, 1,25-dihydroxy-vitamin D3. 
neural development and affect differentiation of neural crest-derived cells. RA is known to inhibit proliferation and stimulate morphological differentiation in neuroblastoma (Haussler et al., 1983; Kaplan et al., 1993) and teratocarcinoma (Strickland et al., 1980; JonesVilleneuve et al., 1982) cells. This retinoid has been recently found to increase the expression of low-affinity neurotrophin receptors in $\mathrm{PC} 12$ cells (Scheibe and Wagner, 1992) and to promote neurite outgrowth in mutant cell lines derived from PC12 cells that are deficient in cyclic AMP-dependent protein kinase (Scheibe et al., 1991).

In the present study we have examined the effect of RA and other ligands of the nuclear receptor superfamily in PC12 cells. Our data show that RA, but not triiodothyronine (T3) or vitamin D3, blocks proliferation and produces cell clumping. In addition, RA causes a transient expression of the $p 75^{\text {LNGFR }}$ and TH genes similar to that observed during NGF-induced neuronal differentiation. Therefore, the RA receptors in combination with neurotrophic receptors could play an important role in the proliferation and fate of the sympathoadrenal precursors of the neural crest.

\section{EXPERIMENTAL PROCEDURES}

\section{Cell cultures}

PC12 cells were cultured in RPMI medium containing $10 \%$ donor horse serum (Quality Biological, Gaithersburg, MD, U.S.A.) and $5 \%$ fetal calf serum (GIBCO, Grand Island, NY, U.S.A.) in collagen-treated plates. The cells were incubated with the different factors at the concentrations and for the times indicated in the figures. The incubations were performed either in high-serum conditions, in the medium indicated above, or in low-serum conditions (medium containing $0.5 \%$ of a $2: 1$ mixture of donor horse serum:fetal calf serum). 7S NGF, dexamethasone (Dx), RA, and T3 were from Sigma (St. Louis, MO, U.S.A.). Basic fibroblast growth factor (bFGF), insulin-like growth factor-1 (IGF1 ), and epidermal growth factor (EGF) were obtained from Boehringer Mannheim (Mannheim, Germany), and 1,25dihydroxy-vitamin D3 (VD) was a gift from Hoffmann-La Roche (Basel, Switzerland).

\section{Cell proliferation and morphological differentiation}

Cell morphology was assessed by phase-contrast microscopy with an inverted microscope, and pictures were taken with a Nikon-F2 camera at a magnification of $200 \times$. For morphology studies the cells were seeded at an initial density of 10,000 cells per well using 24 -well multidishes and treated with the different hormones as indicated in the corresponding figures.

Cell proliferation was assessed by counting the total number of cells or by analysis of $\left[{ }^{3} \mathrm{H}\right]$ thymidine incorporation. In the first case the cells were seeded in 24-well plates. After the different treatments the cells were harvested from the plastic surface, and the number of cells per culture was counted using a hemocytometer. Analysis of $\left[{ }^{3} \mathrm{H}\right]$ thymidine incorporation was performed in 96-well plates containing 10,000 cells per plate in $100 \mu \mathrm{l}$ of medium per well. The cells were incubated with the different factors in high- or low-serum conditions as indicated with $0.1 \mu \mathrm{Ci}$ of $\left[{ }^{3} \mathrm{H}\right]$ thymidine for the last $6 \mathrm{~h}$. The incorporated $\left[{ }^{3} \mathrm{H}\right]$ thymidine was collected with a cell harvester and analyzed by liquid scintillation counting. All treatments were performed in quadruplicate cultures, and the results did not vary by more than $5-15 \%$.

\section{RNA extraction and hybridization}

Total RNA was extracted from the cell cultures with guanidine thiocyanate (Chomczynski and Sacchi, 1987). The RNA was electrophoresed in 1\% formaldehyde-agarose gels and transferred to nylon-nitrocellulose membranes (Nytran) for northern blot analysis. The RNA was stained with $0.02 \%$ methylene blue. The blots were hybridized with cDNA probes for rat TH (Grima et al., 1985), p75 ${ }^{\text {LNGFR }}$ (Radeke et al., 1987), or Trk (Loeb et al., 1991) labeled by random oligonucleotide priming. Hybridizations were at $42^{\circ} \mathrm{C}$ with $50 \%$ formamide, and the more stringent wash was at $42^{\circ} \mathrm{C}$ with $0.1 \times$ saline-sodium citrate containing $0.1 \%$ sodium dodecyl sulfate. The mRNA levels were quantified by densitometric scanning of the autoradiograms. The values obtained were corrected by the amount of RNA applied in each lane, which was determined by densitometry of the stained membranes.

\section{Reporter plasmids and expression vectors}

The plasmid $\triangle \mathrm{MTV}-\mathrm{TRE}_{\mathrm{PAL}}$ was constructed (Umesono et al., 1988) by replacing the glucocorticoid-responsive elements present in the mouse mammary tumor virus-long terminal repeat (MMTV-LTR) with an oligonucleotide that encodes the perfect palindromic T3/RA response element $\left(\mathrm{TRE}_{\mathrm{PAL}}\right.$ ) fused to the chloramphenicol acetyltransferase (CAT) gene. The parental construct was used as a glucocorticoid-responsive promoter. The plasmid R140-Luc, which contains 140 bp of the RAR $\beta 2$ promoter ligated to the luciferase gene, has a RA response element (Vivanco-Ruiz et al., 1991). Oligonucleotides containing direct repeats (DRs) of the consensus sequence AGGTCA separated by four or five nucleotides were cloned upstream of the $t k$ promoter driving the expression of the CAT gene (DR4-tk-CAT and DR5-tk-CAT constructs). DR4 and DR5 elements function as T3 and RA response elements, respectively (Umesono et al., 1991). The expression vectors for the receptors consisting of the RSV promoter ligated to the thyroid hormone receptor (TR) chick c-erbA $\alpha$ ( Sap et al., 1986) or the human retinoic acid receptor $\operatorname{RAR} \alpha$ (Umesono et al., 1988) and the human RXR $\alpha$ (Mangelsdorf et al., 1990) cloned into the expression vector $\mathrm{pSG}-5$, have been described previously.

\section{DNA transfection}

For transient expression assays the cells were plated in 60-mm-diameter Petri dishes $24 \mathrm{~h}$ before transfection by the calcium phosphate method. The cells were transfected with $5 \mu \mathrm{g}$ of reporter constructs. After overnight incubation with the calcium phosphate precipitate, the cells were incubated with the different ligands for $48 \mathrm{~h}$. Each treatment was performed in duplicate cultures that showed $<5 \%$ variation in CAT or luciferase activity. CAT activity was determined by incubation of $\left[{ }^{14} \mathrm{C}\right]$ chloramphenicol with $50 \mu \mathrm{g}$ of cell lysate protein. After autoradiography, the nonacetylated and acetylated $\left[{ }^{14} \mathrm{C}\right]$ chloramphenicol was quantified, and the data are expressed as percentages of acetylated forms after each treatment. Luciferase activity was determined in the cell extracts using the Luciferase Assay System from Promega. In cotransfection experiments the cells were transfected with 5 
FIG. 1. Influence of RA and T3 on $P C 12$ cell morphology shown in phase-contrast micrographs of cells treated with different factors for 5 days: (A) control; (B) $50 \mathrm{ng} / \mathrm{ml}$ of NGF; (C) $100 \mathrm{nM} \mathrm{Dx}$; (D) $50 \mathrm{ng} / \mathrm{ml}$ of NGF $+100 \mathrm{nM}$ of Dx; (E) $1 \mu M \mathrm{RA}$; (F) $50 \mathrm{ng} / \mathrm{ml}$ of NGF $+1 \mu M$ RA; (G) $5 \mathrm{nM} \mathrm{T3}$; and $(\mathbf{H}) 5 \mathrm{nM}$ T3 $+50 \mathrm{ng} / \mathrm{ml}$ of NGF.

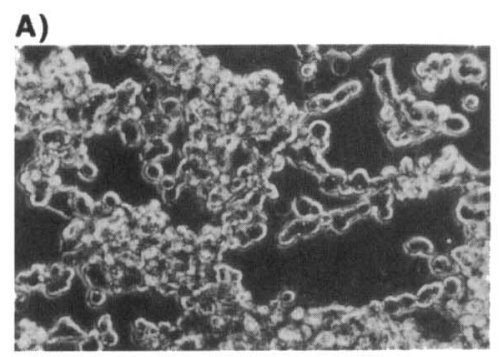

c)

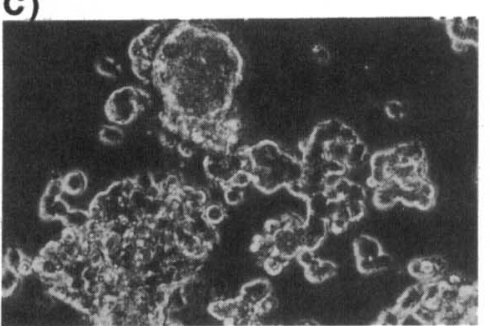

E)

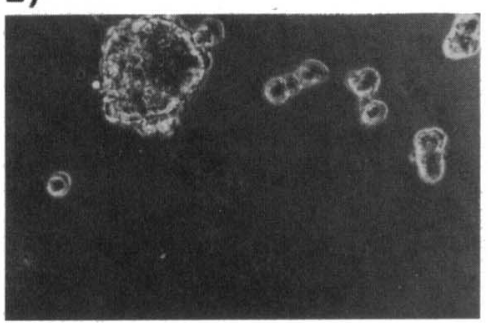

G)

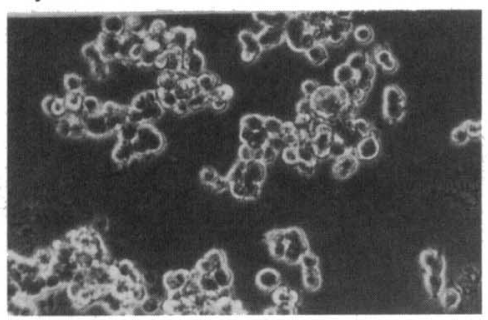

B)

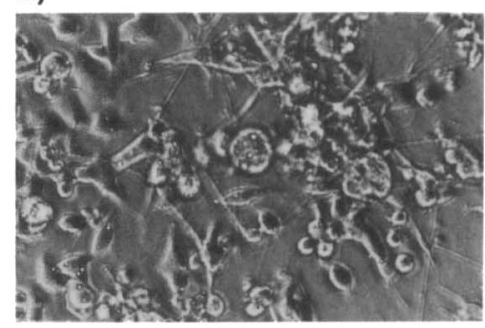

D)

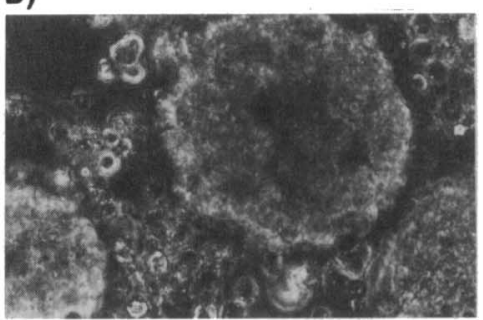

F)

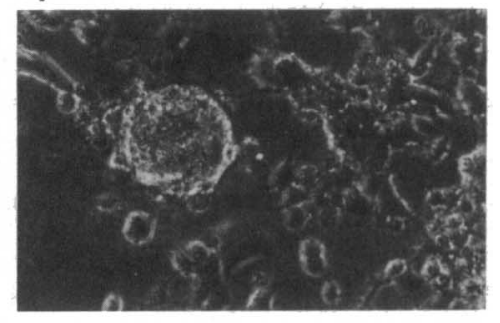

H)

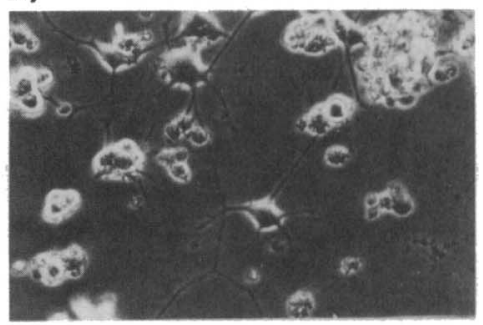

$\mu \mathrm{g}$ of the reporter plasmid and the indicated amounts of the corresponding receptor expression vector. The total amount of DNA was kept constant by addition of an "empty" expression vector.

\section{RESULTS}

Morphological effects of RA in PC12 cells

Figure 1 shows the effect of treatment for 5 days with NGF, RA, Dx, and T3 on the morphology of PC12 cells. Control cells are shown in Fig. 1A. As expected, neurite outgrowth was observed in NGFtreated cells (Fig. 1B), whereas RA (Fig. 1E) induced formation of cell clusters without neurite extension. The phenotype induced by RA was similar to that caused by glucocorticoids (Fig. 1C), which induce chromaffin differentiation. The combination of NGF and RA (Fig. 1F) or NGF and Dx (Fig. 1D) produced a mixed phenotype in which part of the cell population had neurites and other formed clumps. As can be observed in Fig. $1 \mathrm{G}$ and $\mathrm{H}, \mathrm{T} 3$ did not alter PC12 cell morphology or its response to NGF. The phenotype observed in VD-treated cells was also indistinguishable from that found in control cultures (data not shown).

\section{RA inhibits proliferation of PC12 cells}

In addition to inducing formation of cell clusters, RA inhibits the division of PC12 cells. Cell proliferation was assessed by counting the total number of cells per culture and by determining DNA synthesis after incubation with $\left[{ }^{3} \mathrm{H}\right]$ thymidine. Figure $2 \mathrm{~A}$ compares the growth curve obtained in the presence of $15 \%$ serum in control PC12 cells and in cells incubated with 0.01 and $1 \mu M$ RA alone or in combination with $5 \mathrm{n} M$ T3. The growth rate was reduced in cells treated with RA. However, T3 did not alter either normal cell growth or the inhibition caused by RA. Figure $2 \mathrm{~B}$ 


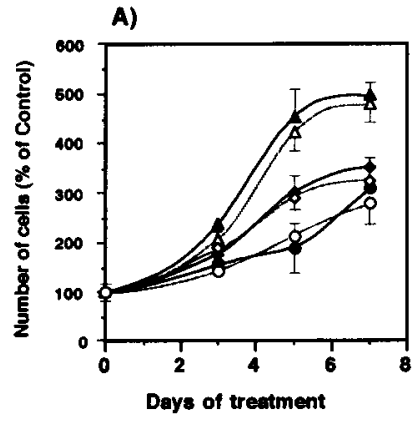

B)

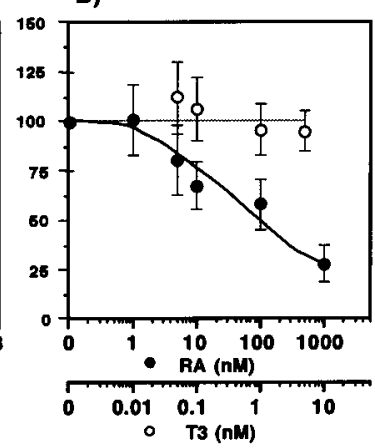

FIG. 2. Influence of RA and $\mathrm{T} 3$ on $\mathrm{PC} 12$ cell proliferation. A: Cultures of PC12 cells grown with $15 \%$ serum were incubated with $10 \mathrm{nM}$ or $1 \mu M \mathrm{RA}$ in the presence or absence of $5 \mathrm{nM}$ T3 as indicated. At different intervals the number of cells was counted in these groups as well as in groups of control untreated cells: control $(-\mathbf{\Delta}-) ; 10 \mathrm{nM}$ RA $(-\bullet-) ; 1 \mu M$ RA $(-\bullet) ; 5 n M$ T3 $(-.-\triangle---) ; 5 n M$ T3 + $10 \mathrm{nM}$ RA $(--\diamond---)$; and $5 \mathrm{n} M$ T3 $+1 \mu M$ RA $\left(---\mathrm{O}_{---)}\right.$. B: Cell number was determined in cells incubated for 5 days with increasing concentrations of RA $(\bullet)$ or T3 $(O)$. Data are mean $\pm \mathrm{SD}$ (bars) values of quadruplicate cultures and are expressed as percentages of the corresponding control cultures.

shows the effect of 5 days of incubation with increasing concentrations of T3 and RA on cell number. RA produced a dose-dependent inhibition with a half-maximal effect found at $\sim 50-100 \mathrm{n} M$. After 5 days $1 \mu M$ RA reduced the number of cells by approximately $75 \%$. However, T3 did not affect cell proliferation at any of the concentrations examined.

As DNA synthesis could have continued in the presence of RA even in the absence of cell division, $\left[{ }^{3} \mathrm{H}\right]-$ thymidine incorporation was determined in cells incubated with increasing concentrations of RA. Figure 3A shows that RA produced a dose-dependent decrease in $\left[{ }^{3} \mathrm{H}\right]$ thymidine incorporation in $\mathrm{PC} 12$ cells. A halfmaximal effect was again found at $\sim 100 \mathrm{n} M$, and the effect of $1 \mu M$ RA was almost maximal. The highest concentration used, $10 \mu M$, reduced incorporation of $\left[{ }^{3} \mathrm{H}\right]$ thymidine by $\sim 70 \%$. From these results and from those shown in Fig. 2 it can be inferred that RA inhibited cell division and DNA replication equivalently. It is well known that in addition to inducing neurite formation, NGF inhibits division of $\mathrm{PC} 12$ cells. Figure $3 \mathrm{~B}$ shows the dose dependence of this inhibition. NGF produced a maximal reduction in DNA synthesis at 50 $\mathrm{ng} / \mathrm{ml}$, and as shown in Fig. 3C, the combination of NGF plus RA did not cause a further inhibition of cell growth. T3 and VD did not affect DNA synthesis in PC12 cells (data not shown).

\section{Influence of RA and NGF on DNA synthesis in} PC12 cells in low-serum conditions

To test whether the antiproliferative effect of RA on $\mathrm{PC} 12$ cells requires the presence of other serum constituents, additional studies were carried out in cells cultured with low serum $(0.5 \%)$. Figure $4 \mathrm{~A}$ shows that RA also significantly reduced $\left[{ }^{3} \mathrm{H}\right]$ thymidine incorporation under these culture conditions. In contrast, neither T3 nor VD affected $\left[{ }^{3} \mathrm{H}\right]$ thymidine incorporation. Dx was also ineffective. It is surprising that the reduction of DNA synthesis caused by NGF in highserum conditions was no longer present when the cells were incubated with the growth factor in low-serum conditions. In fact, as it can be observed in Fig. 4B, NGF increased incorporation to a similar extent as that produced by IGF-1 or EGF, both of which are known to be mitogenic for PC12 cells. Furthermore, bFGF, which produces neurite extension in these cells, also increased $\left[{ }^{3} \mathrm{H}\right]$ thymidine incorporation in low-serum conditions. As shown in Fig. 4C, the effect in DNA synthesis produced by NGF was dose dependent, increasing by about twofold with respect to control values at $50-100 \mathrm{ng} / \mathrm{ml}$ of NGF.

Regulation of the activity of constructs containing T3/RA-responsive sequences in PC12 cells

Nuclear receptors regulate transcription by binding to short cis-acting DNA sequences named hormone
A)

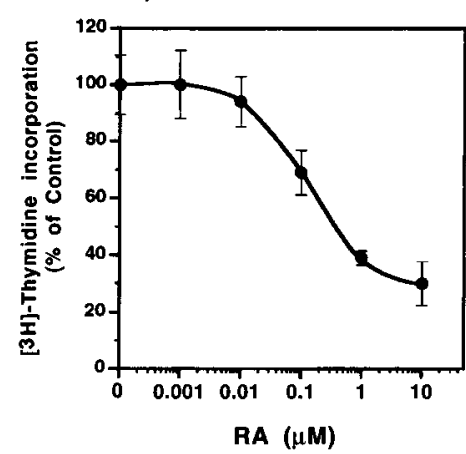

B)

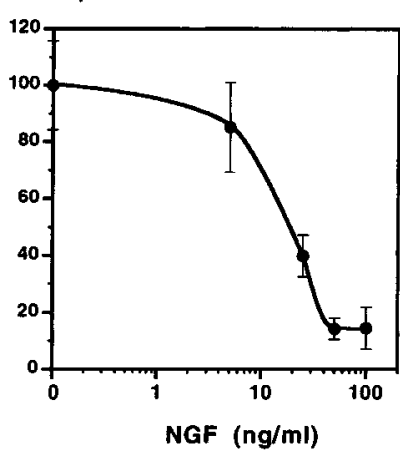

C)

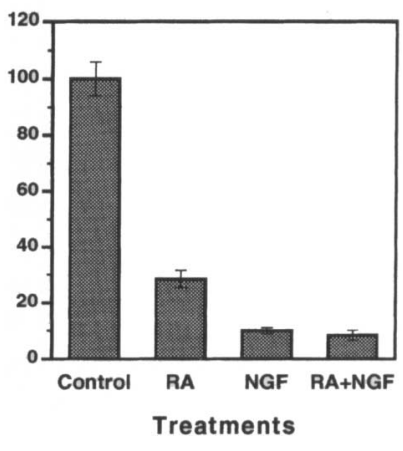

FIG. 3. Comparison of the influence of RA and NGF on $\left[{ }^{3} \mathrm{H}\right]$ thymidine incorporation in PC12 cells. $\mathbf{A}$ and $\mathbf{B}$ : The cells were incubated in medium containing $15 \%$ serum with the concentrations of RA or NGF indicated for $48 \mathrm{~h}$ and with $1 \mu \mathrm{Ci} / \mathrm{ml}$ of $\left[{ }^{3} \mathrm{H}\right]$ thymidine for the last $6 \mathrm{~h}$. C: The cells were incubated for $48 \mathrm{~h}$ with $1 \mu \mathrm{MRA}, 50 \mathrm{ng} / \mathrm{ml}$ of NGF, or the combination of both. Data are mean $\pm \mathrm{SD}$ (bars) values of four different cultures. 
A)

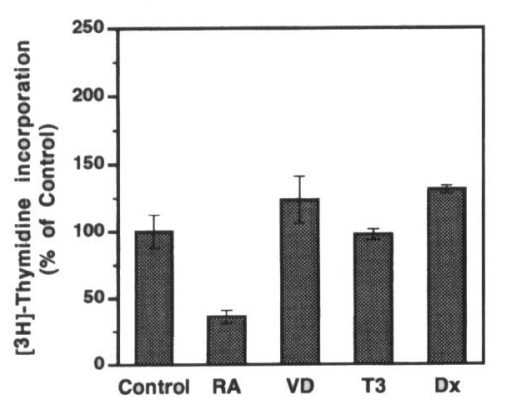

B)

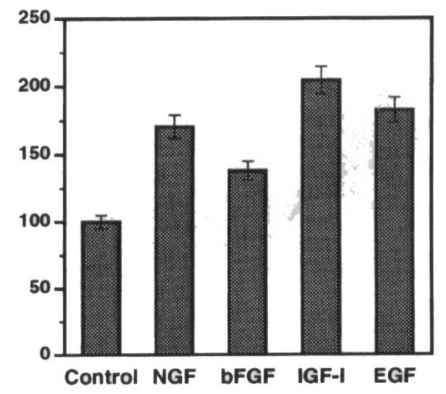

C)

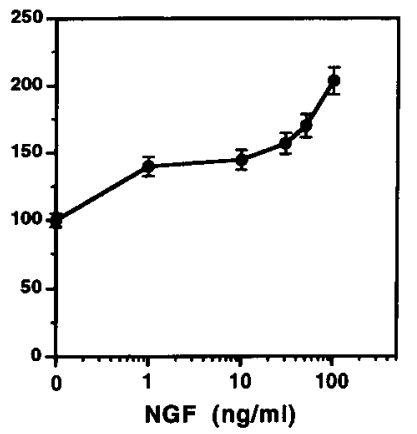

FIG. 4. RA but not NGF decreases DNA synthesis in PC12 cells grown in low serum. The cells were incubated for $48 \mathrm{~h}$ in medium containing $0.5 \%$ serum in the presence of the hormones and growth factors indicated: (A) $1 \mu M$ RA, $100 \mathrm{n} M \mathrm{VD}, 5 \mathrm{n} M$ T3, or 100 $\mathrm{nM} \mathrm{Dx}$ and (B) $50 \mathrm{ng} / \mathrm{ml}$ of NGF, $80 \mathrm{ng} / \mathrm{ml}$ of bFGF, $38 \mathrm{ng} / \mathrm{ml}$ of IGF-1, or $60 \mathrm{ng} / \mathrm{ml}$ of EGF. C: The cells were treated with increasing concentrations of NGF (between 1 and $100 \mathrm{ng} / \mathrm{ml}$ ). $\left[{ }^{3} \mathrm{H}\right]$ Thymidine incorporation was assessed after $6 \mathrm{~h}$ of incubation with the nucleotide in quadruplicate cultures. Data are mean \pm SD (bars) values, expressed as percentages of the values obtained in the corresponding control untreated cells.

response elements that are normally present in the $5^{\prime}-$ flanking region of the regulated genes. Figure 5 shows the effect of RA and T3 on the activity of a reporter construct ( $\triangle \mathrm{MTV}-\mathrm{TRE}_{\mathrm{PAL}}-\mathrm{CAT}$ ) that contains a palindromic thyroid hormone response element (TRE $E_{\mathrm{PAL}}$ ) that also acts as a response element for RA receptors. Whereas incubation with $1 \mu M \mathrm{RA}$ for $48 \mathrm{~h}$ increased CAT activity by approximately twofold, treatment with 5 or $100 \mathrm{n} M$ T3 for the same period did not affect CAT activity. RA also increased the activity of a reporter CAT plasmid containing other strong RA response elements, a DR of the same sequence separated by five nucleotides (DR5) or the natural RAR $\beta 2$ pro- moter, which contains a DR5-type element. In addition, T3 was unable to increase the activity of a construct containing another $\mathrm{T} 3$ response element, a DR separated by four nucleotides (DR4). These results suggest the absence (or low levels) of functional thyroid hormone receptors, which could account for the lack of response of $\mathrm{PC} 12$ cells to T3. Figure $5 \mathrm{~B}$ also shows regulation of the construct MMTV-CAT, which contains several glucocorticoid response elements, by Dx in PC12 cells. Incubation with $100 \mathrm{n} M$ Dx for 48 $h$ produced a strong increase ( $>10$-fold) in the activity of this construct, confirming the presence of high levels of functional glucocorticoid receptors in these cells.
FIG. 5. Activation of reporter plasmids by thyroid hormone, RA, and glucocorticoids in PC12 cells. A: The cells were transfected with $5 \mu \mathrm{g}$ of the construct $\triangle \mathrm{MTV}$-TRE $\mathrm{PAL}_{\mathrm{PA}}$ CAT, which contains a common response element for thyroid hormone and retinoic acid receptors; the T3-responsive plasmid DR4-tk-CAT; or the RA-responsive constructs DR5-tk-CAT and R140-Luc. After transfection the cells were incubated with medium alone (control), $1 \mu M \mathrm{RA}$, and 5 or $100 \mathrm{nM}$ T3 for $48 \mathrm{~h}$, and CAT or luciferase activity was determined. B: The cells were transfected with $5 \mu \mathrm{g}$ of the glucocorticoidresponsive construct MMTV-CAT, and CAT activity was determined after $48 \mathrm{~h}$ of incubation with $100 \mathrm{nM}$ Dx. C: The cells were cotransfected with $5 \mu \mathrm{g}$ of the $\Delta \mathrm{MTV}$ TRE $E_{\text {PAL }}-C A T$ plasmid plus $2.5 \mu \mathrm{g}$ of an expression vector for the $\alpha$ form of the RA receptor (RAR) or the $\alpha$ form of the TR $\mathrm{c}$ erbA, alone or in combination with $0.5 \mu \mathrm{g}$ of an expression vector for the retinoid $X$ receptor $R X R \alpha$. The amount of DNA was kept constant among the different transfections by cotransfection of the reporter
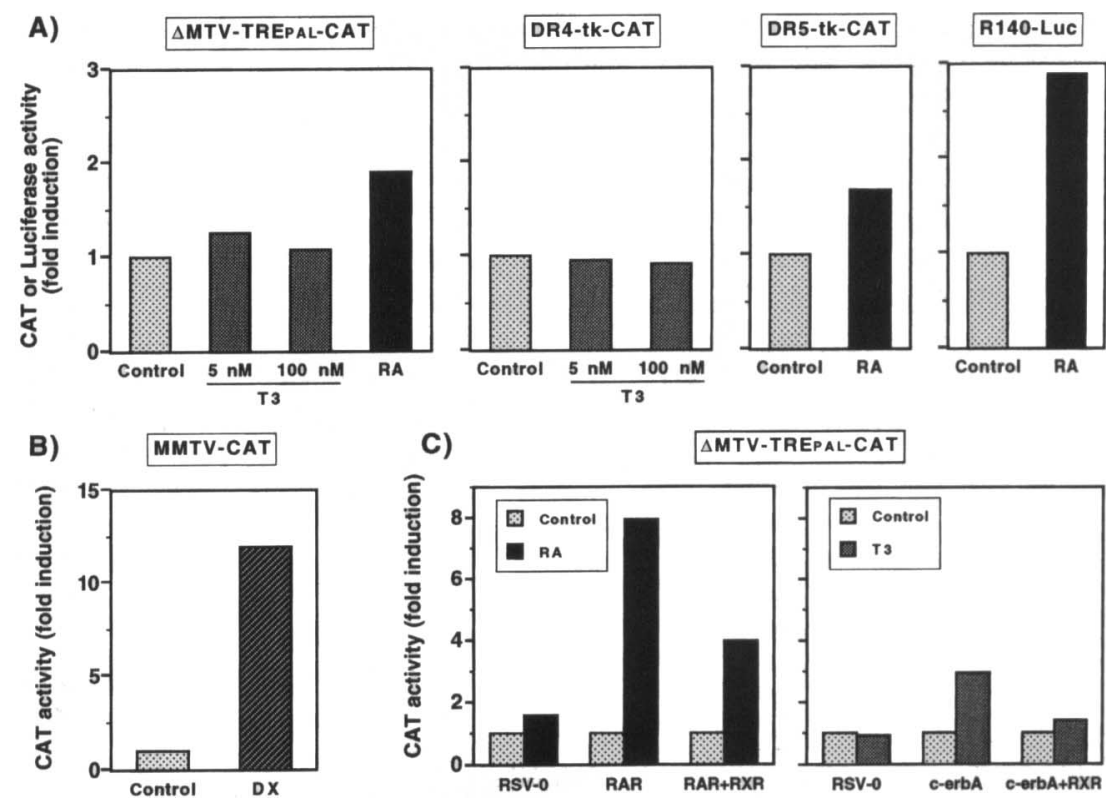

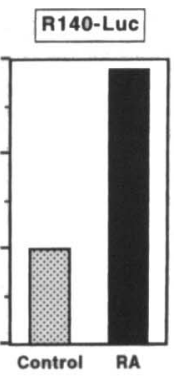

plasmid with the appropriate amounts of an empty expression vector (RSV-0). After transfection the cells were incubated with the corresponding ligand (1 $\mu M$ RA and $5 \mathrm{n} M$ T3, respectively), and CAT activity was determined. The data, which are expressed as fold induction over the values found in control untreated cells, represent the mean of two separate experiments with < $10 \%$ variation. 
A)

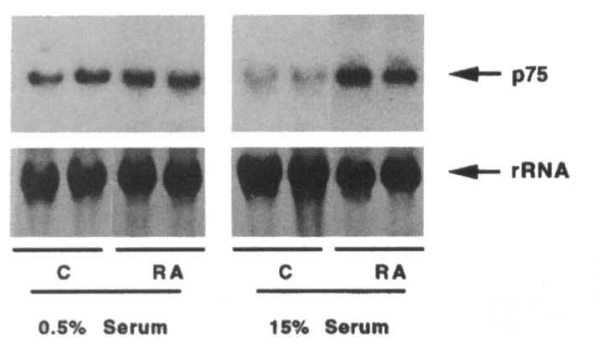

C)

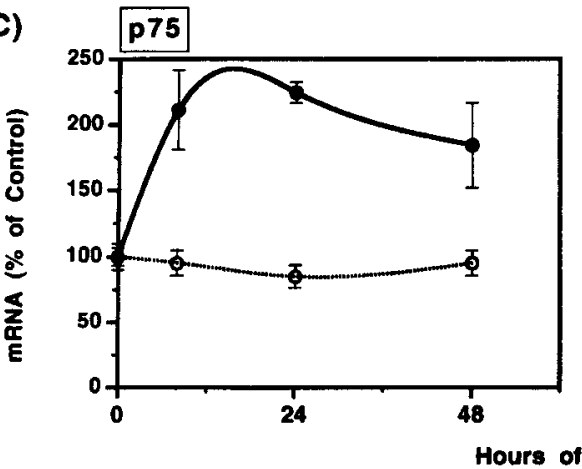

B)
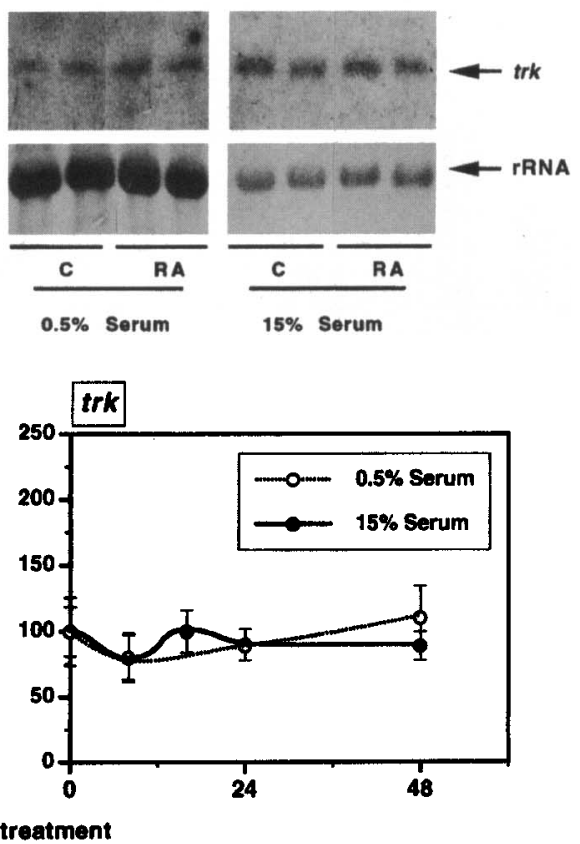

FIG. 6. Effect of RA on $\mathrm{p} 75^{\text {LNGFR }}$ and trk mRNA levels. The upper panels show representative northern blots of $30 \mu \mathrm{g}$ of total RNA from PC12 cells treated with or without [control (C)] $1 \mu M$ RA for $48 \mathrm{~h}$ in medium containing $15 \%$ or $0.5 \%$ serum. The RNA was hybridized with specific cDNA probes for p75 ${ }^{\text {LNGFR }}(\mathbf{A})$ or trk $(\mathbf{B})$. The upper lanes in both panels show the autoradiograms obtained, and the bottom lanes show the staining of the blot with $0.02 \%$ methylene blue. C: Quantification of p $75^{\text {LNGFR }}$ (left panel) and trk (right panel) mRNA levels in cells treated for various intervals with $1 \mu M \mathrm{RA}$ in the presence of $15 \%(\bullet)$ or $0.5 \%$ (O) serum. The autoradiograms were quantitated by densitometry, and the values obtained were corrected by the amount of RNA applied in each lane. Data are mean \pm SD (bars) values obtained from two separate blots each containing duplicate samples, expressed as percentages of the values obtained in the corresponding control cells.
The influence of overexpression of T3 and RA receptors on the transcriptional response to their corresponding ligands is shown in Fig. 5C. After transfection with an expression vector for $\operatorname{RAR} \alpha$, the response of $\triangle$ MTV-TRE PAL $^{-C A T}$ to RA was increased markedly, from two- to eightfold, relative to the values obtained with the endogenous receptors showing that $\mathrm{RA}$ receptors are present in limiting concentrations in PC1 2 cells. Although CAT activity was not affected by $\mathrm{T} 3$ in control transfections, a threefold increase was observed after incubation with T3 in cells transfected with the receptor $\operatorname{TR} \alpha$. Recent evidence has shown that the retinoid receptor RXR can heterodimerize with TRs and RARs and that heterodimerization enhances affinity for the response elements. Figure $5 \mathrm{C}$ shows the influence of transfection with $\mathrm{RXR} \alpha$ on the response to T3 and RA. Unexpectedly, the response to RA was lower in PC12 cells transfected with the combination of RAR and RXR than in cells transfected with RAR alone. Similarly, the response to T3 was significantly decreased in cells overexpressing RXR together with TR.

\section{Influence of RA, NGF, and Dx on $t r k, p 75^{\text {LNGFR }}$ and TH mRNA levels}

Figure 6 illustrates the effect of RA on the expression of the genes encoding the NGF receptors (the trk protooncogene and the low-affinity receptor p $75^{\text {LNGFR }}$ ). In the presence of $15 \%$ serum RA caused a significant increase of $\mathrm{p} 75^{\mathrm{LNGFR}} \mathrm{mRNA}$ levels (Fig. 6A) without altering trk expression (Fig. 6B). The increase in $\mathrm{p} 75^{\mathrm{LNGFR}}$ mRNA content was already maxi- mal after $8 \mathrm{~h}$ of incubation and was maintained for at least $48 \mathrm{~h}$ (Fig. 6C). However, RA did not alter the abundance of $\mathrm{p} 75^{\mathrm{LNGFR}} \mathrm{mRNA}$ at any of the periods examined in low serum (Fig. 6C). The effect of NGF was very similar to that caused by the retinoid. NGF increased the level of $\mathrm{p} 75^{\mathrm{LNGFR}}$ transcripts only in cells grown in the presence of $15 \%$ serum (Fig. 7) with similar kinetics and to a similar extent to that shown by RA. Figure 8 (left panel) compares the influence of a 48-h incubation with RA, NGF, or Dx, under both serum conditions, on $\mathrm{p} 75^{\mathrm{LNGFR}} \mathrm{mRNA}$. Whereas RA, $\mathrm{NGF}$, or the combination of both increased levels of this transcript in high serum, incubation with Dx did not regulate the level of this mRNA. Furthermore, the glucocorticoid produced a significant decrease in p $75^{\text {LNGFR }}$ mRNA levels in cells grown in low-serum conditions. However, none of these compounds regulated trk expression (Fig. 8, right panel). Neither T3 nor VD affected $\mathrm{p} 75^{\mathrm{LNGFR}}$ or trk mRNA levels (data not shown).

TH catalyzes an early and limiting step in the biosynthesis of catecholamines. Although this enzyme is expressed in both the neuronal and endocrine derivatives of the sympathoadrenal lineage, glucocorticoid induction of TH is considered to be the best biochemical marker of chromaffin differentiation. However, as shown in Fig. 9A, NGF also produced an increase in TH mRNA expression in PC12 cells. This increase was transient, being maximal after $8-16 \mathrm{~h}$ and decreasing to values even lower than the basal levels after a 48-h incubation. The influence of RA on TH gene expression was again similar to that found with NGF. 
A)

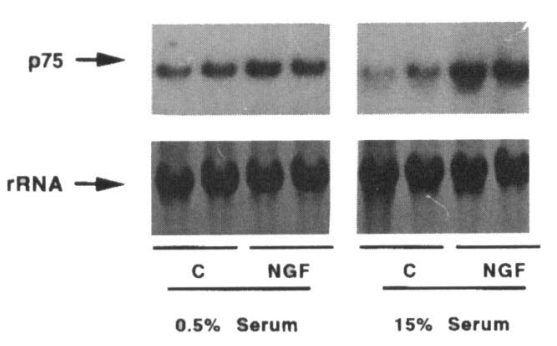

B)

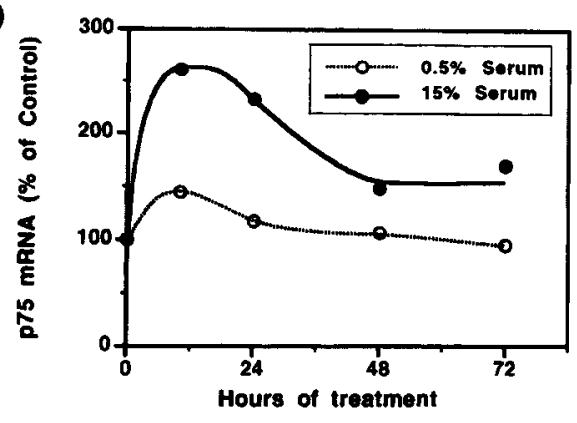

C)

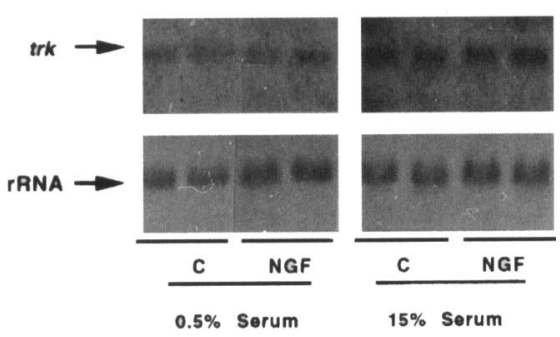

FIG. 7. NGF increases $p 75^{\text {LNGFR }}$ mRNA levels in PC12 cells. A: Northern blots of total RNA from cells incubated with $50 \mathrm{ng} / \mathrm{ml}$ of NGF for $48 \mathrm{~h}$ in high- and low-serum conditions hybridized with a $\mathrm{p} 75^{\mathrm{LNGFR}} \mathrm{CDNA}$ probe. $\mathrm{C}$, control. The autoradiograms are shown in the upper lanes and the stained blots in the lower lanes. B: Quantification of $\mathrm{p} 75^{\mathrm{LNGFR}} \mathrm{mRNA}$ levels in cells treated with NGF for the indicated intervals in medium containing $15 \%$ $(\bullet)$ or $0.5 \%(O)$ serum. C: Representative northern blots of RNA from PC12 cells treated with $50 \mathrm{ng} / \mathrm{ml}$ of NGF for $48 \mathrm{~h}$ and hybridized with a trk cDNA probe. Data are mean values of duplicate samples, expressed as percentages of the mRNA values obtained in control cells.
RA transiently increased TH mRNA levels with a maximal induction at $16 \mathrm{~h}$ and then a decrease below control values after $48 \mathrm{~h}$ of incubation with the retinoid. Figure 9A also shows that the combined effect of NGF and RA at $8 \mathrm{~h}$ of incubation was synergistic and that under these conditions TH mRNA levels increased by a factor of four- to fivefold. However, as shown in Fig. $9 \mathrm{~B}$, the decrease caused after $48 \mathrm{~h}$ of incubation with RA was similar in the presence or absence of NGF. Figure 9B also illustrates that glucocorticoids induced a sustained increase of TH mRNA levels. After incubation with Dx for $48 \mathrm{~h}$, the content of this transcript was elevated above control levels. The combination of Dx with NGF or RA did not significantly alter the response to the glucocorticoid. Neither T3 (Fig. 9C) nor VD (data not shown) affected TH mRNA levels.

\section{DISCUSSION}

We have analyzed the morphological and biochemical effects of RA in PC12 cells. The change induced by RA in these cells is characterized by the arrest of the cells in a nondividing state, by the formation of cell aggregates with pseudosyncytial appearance, by an induction of low-affinity neurotrophin receptors, and by a transient expression of the $\mathrm{TH}$ gene.

RA produced a strong decrease in the proliferation of PC12 cells. Strong antimitogenic effects of RA have been observed in many types of neural and nonneural transformed cells, and the retinoids are currently being used in the treatment of different tumors. Our data show that the antiproliferative effects of RA were observed even in low-serum culture conditions that are restrictive for proliferation. Confirming previous observations (Greene and Tischler, 1976), NGF-induced differentiation of PC12 cells was also characterized by arrested cell growth in the presence of high serum, but we also find an increase rather than a decrease in DNA synthesis in PC12 cells incubated for 2 days with NGF under low-serum conditions. The cells that showed increased DNA synthesis also underwent morphological differentiation with neurite extension. This finding, which had not been previously reported for PC12 cells, agrees with the observation that NGF has both mitogenic and antimitogenic activity in the $\mathrm{PC} 12$ variant
FIG. 8. Comparison of the effect of glucocorticoids, NGF, and RA on p $75^{\text {LNGFF }}$ and trk mRNA. Total RNA was extracted from control PC12 cells and from cells incubated for $48 \mathrm{~h}$ with $1 \mu M$ RA, $50 \mathrm{ng} / \mathrm{ml}$ of NGF, the combination of both (RA $+\mathrm{NGF})$, or $100 \mathrm{nM}$ Dx in medium with $15 \%(\bullet)$ and $0.5 \%(O)$ serum.

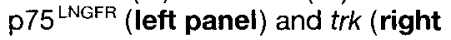
panel) mRNA levels were quantified as described in Fig. 6. Data are mean $\pm S D$ (bars) values obtained from two different experiments performed in duplicate.

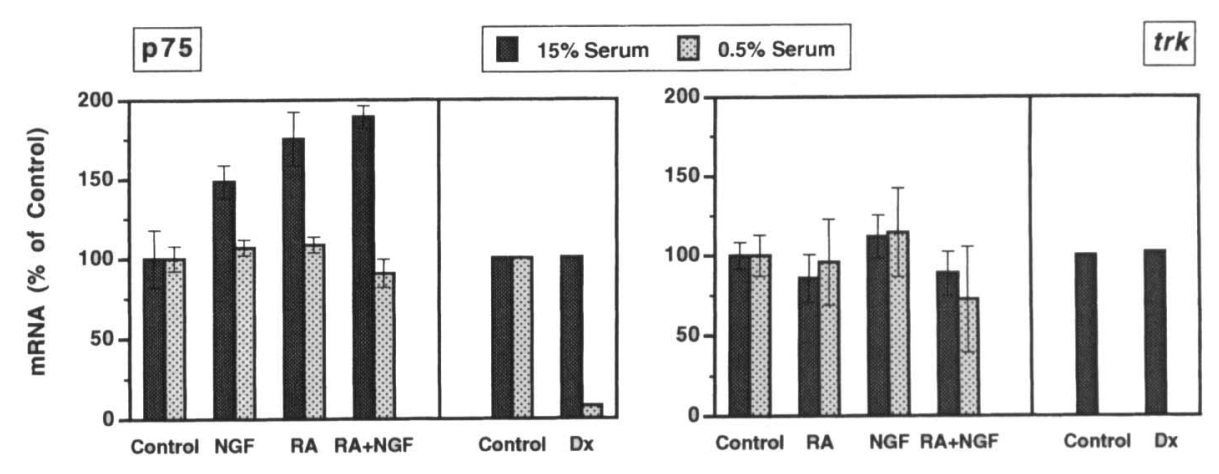


A)

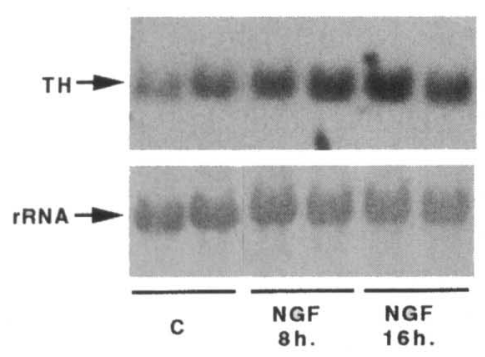

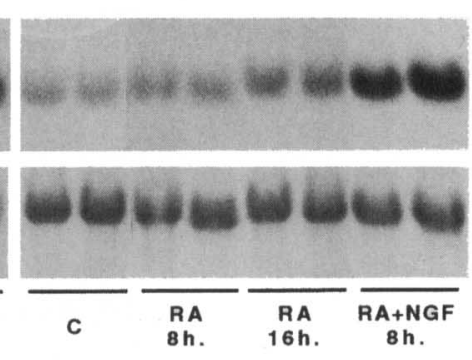

B)

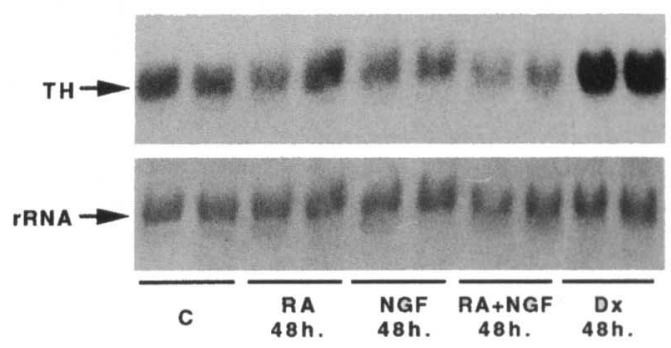

C)

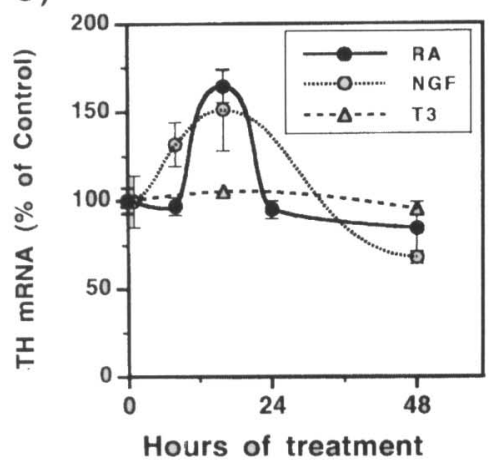

D)

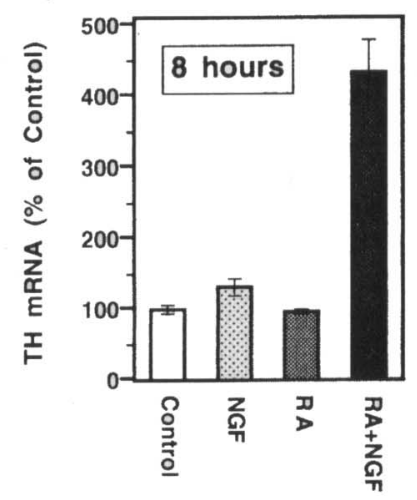

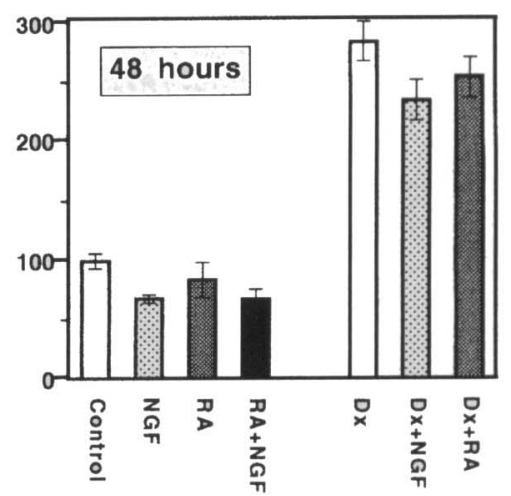

FIG. 9. Regulation of TH mRNA levels by RA, NGF, and Dx. Representative northern blots were obtained with $30 \mu \mathrm{g}$ of total RNA from PC12 cells treated with (A) $1 \mu M$ RA or $50 \mathrm{ng} / \mathrm{ml}$ of NGF for 8 or $16 \mathrm{~h}$ or the combination of both for $8 \mathrm{~h}$ or (B) NGF, RA, the combination of both, or $100 \mathrm{nM} \mathrm{Dx}$ for $48 \mathrm{~h}$. C, control. The upper lanes show the TH transcripts, and the lower lanes the stained

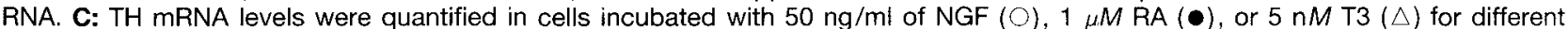
periods ranging from 0 to $48 \mathrm{~h}$ as indicated. D: Quantification of TH mRNA levels in cells treated with NGF, RA, Dx, or their combinations for $8 \mathrm{~h}$ (left panel) or $48 \mathrm{~h}$ (right panel). All treatments were performed at least in duplicate in medium with $15 \%$ serum. Data are mean $\pm \mathrm{SD}$ (bars) values of the corresponding control values.

sublines U2 and U7 (Burstein and Greene, 1982) and with the recent description that rat chromaffin cells in vitro show a large proliferative response to NGF followed by neuronal differentiation (Tischler et al., 1993).

RA effects in cells are mediated by nuclear receptors that are very similar to $\mathrm{T} 3$ and $\mathrm{VD}$ receptors. Both T3 and VD play an important role in growth and developmental processes and regulate proliferation and differentiation of many cell types. In particular, T3 plays a crucial role in neural development as exemplified by the fact that thyroid hormone deprivation during development leads to brain damage (Dussault and Rouel, 1987). However, in contrast with the observed effects of RA, neither T3 nor VD altered PC12 cell proliferation or differentiation. The nuclear receptors regulate gene expression by binding to cis-acting sequences and increasing or decreasing transcription (for recent reviews, see Lazar, 1993; Guiguère, 1994). Hormone response elements have been identified in several genes and consist in palindromic or DRs of the consensus sequence AGGTCA. A DR5 acts as an RA response element, a DR4 as a T3 response element, and a DR3 as a vitamin D3 response element (Umesono et al.,
1991). The close similarity among RA, T3, and VD receptors makes it possible that some of these DNA motifs can act as a common response element for more than one receptor. This is the case with the palindromic element that confers regulation to the MMTV promoter by T3 and RA (Umesono et al., 1988). We observed that RA, but not T3, increased the activity of this promoter in PC12 cells. In addition, we found stimulation of DR5 elements by RA in PC12 cells, whereas a DR4 element is not stimulated by $\mathrm{T} 3$ even at high ligand concentrations. We also observed an increase in the regulation by RA when the levels of RAR were elevated, showing that these receptors are present in limiting amounts in these cells. Furthermore, we found transcriptional regulation by $\mathrm{T} 3$ when the concentrations of TR $\alpha$ were increased in PC12 cells. This result suggests that the nonresponsiveness to T3 may in fact be due to the low level of endogenous thyroid hormone receptors in these cells. This is strongly supported by the finding that stable overexpression of the TR $\alpha$ gene in PC12 cells using a retroviral vector regulates NGFdependent differentiation in a T3-dependent fashion (Muñóz et al., 1993).

Recent results have shown that heterodimerization 
with RXR can increase affinity of RARs and TRs to the palindromic hormone response element and increase the effectiveness of the corresponding ligands (García-Villalba et al., 1993). However, we observed a significant reduction in the response to T3 and RA when RXR was overexpressed in PC12 cells in combination with either TR or RAR. This suggests that the endogenous RXR receptors were in an optimal concentration and that overexpression of these receptors leads to squelching of nuclear factors that are needed for maximal transcription rates. Alternatively, an excess of RXR could lead to the formation of RXR homodimers, which could displace the more active heterodimers from the DNA element.

Two classes of NGF receptors have been identified (Johnson et al., 1986; Klein et al., 1991). Although the specific roles of the low- and high-affinity NGF receptors have not yet been totally elucidated (Hempstead et al., 1991; Klein et al., 1991), both p $75^{\text {LNGFR }}$ and trk are likely to be important components of the NGF signal transduction pathway. In agreement with a recent report (Scheibe and Wagner, 1992), we find that the level of $\mathrm{p} 75^{\mathrm{LNGFR}}$ mRNA was increased by $\mathrm{RA}$ in PC12 cells grown in the presence of $15 \%$ serum. In addition, we demonstrate here that this effect of the retinoid does not occur in low-serum conditions, suggesting that other serum constituents are required for this regulation. In contrast with data obtained in chick sympathetic neurons (Rodriguez-Tebar and Rohrer, 1991), the abundance of trk transcripts was not altered by RA in PC12 cells. The increase in the expression of the $\mathrm{p} 75^{\mathrm{LNGFR}}$ gene, which encodes a common low-affinity receptor for the different neurotrophins, indicates a possible role of RA in increasing the responsiveness not only to NGF (Hantzopoulos et al., 1994 ), but also to other neurotrophins during neuronal differentiation.

An increase in its own low-affinity receptor expression by NGF had been previously reported (Doherty et al., 1988; Miller et al., 1991). Our data show that RA closely mimicked the effect of NGF on $p 75^{\text {LNGFR }}$ gene expression. Both the time course and the extent of the induction caused by NGF and RA were identical. However, we and others (Yakovlev et al., 1990) observe a decrease rather than an increase in number of low-affinity NGF receptors after incubation with Dx, which directs PC12 cells toward a chromaffin differentiation pathway. Therefore, RA and NGF caused a similar effect on $\mathbf{p} 75^{\text {LNGFR }}$ gene expression, and this effect was different from that produced by glucocorticoids.

The TH gene, whose product is the enzyme that catalyzes the rate-limiting step in catecholamine biosynthesis, plays an important role in the function of cells of the sympathoadrenal lineage. An increase in TH content is normally considered to be a good marker for chromaffin differentiation of PC12 cells. Previous studies have shown that long exposure times of PC12 cells to NGF decrease TH enzyme activity (Greene and Tischler, 1976). However, more recent work has shown an earlier induction of TH gene expression by NGF (Leonard et al., 1987). Our results show that there was first a transient increase of TH mRNA level at $8-16 \mathrm{~h}$ of treatment with NGF, followed by a longer-term decrease relative to control levels. RA also mimicked the effects of NGF on the expression of the TH gene in PC12 cells and had a biphasic effect on TH mRNA levels.

In contrast to NGF and RA, for which TH mRNA induction is transient, the effect of glucocorticoids on TH gene expression is more sustained (Lewis et al., 1983 ). Thus, after 2 days of treatment, when the TH mRNA content was significantly higher in Dx-treated than in control cells, the level of this mRNA was reduced in RA- and NGF-treated cells.

Induction of $\mathrm{c}$-fos and probably other immediate early genes appears to contribute to the NGF-induced transcription of the $\mathrm{TH}$ gene (Gizang-Ginsberg and Ziff, 1994). It is still not known whether Fos plays any role in the regulation by $\mathrm{RA}$ or $\mathrm{Dx}$.

Several neuroblastomas differentiate into cells that are biochemically and electrophysiologically similar to neurons with neurite extension in the presence of RA (Haussler et al., 1983; Kaplan et al., 1993). However, the retinoid caused cell clustering ( similar to that induced by glucocorticoids) without neurite outgrowth in PC12 cells. Our results suggest that cell aggregation cannot be considered as a marker of chromaffin differentiation in PC12 cells because RA-treated cells do not present a phenotype biochemically chromaffin-like. This is confirmed by the finding that in the PC12 subclone U7, Dx does not produce cell clumping but regulates gene expression in a manner identical to that obtained in the parental cells (J.M.C. and A.A., unpublished data). Therefore, formation of cell aggregates could reflect a change in cell-to-cell contacts independent of differentiation.

The finding that RA mimicks the effect of NGF on $\mathrm{p} 75^{\mathrm{LNGFR}}$ and TH gene expression supports the idea that the retinoid could initiate a program of neuronal differentiation in PC12 cells by blocking cell proliferation and regulating transcription of a set of genes also controlled by the neurotrophin. The expression of a fully neuronal phenotype with neurite extension in RAtreated cells could depend on the interaction with other signaling pathways. This is strongly supported by the finding that in protein kinase A-deficient $\mathrm{PC} 12$ cells RA induces a program of differentiation that is similar to that induced by NGF with neurite outgrowth (Scheibe et al., 1991).

In this work we have demonstrated the important role of RA on the growth, differentiation, and function of pheochromocytoma cells. In the future it will be important to determine the role of the retinoid on the in vivo development of the adrenal medulla and neuronal progenitors as well as the interaction with neurotrophic factors in the signaling of neural crest cell differentiation. 
Acknowledgment: This work has been supported by grants from the Fundación Ramon Areces, DGICYT (PM920002), Comunidad de Madrid (C051/91), and SAF930142 .

\section{REFERENCES}

Burstein D. E. and Greene L. A. (1982) Nerve growth factor has both mitogenic and antimitogenic activity. Dev. Biol. 94, 477482.

Chomczynski P. and Sacchi N. (1987) Single-step method of RNA isolation by acid guanidinium thiocyanate-phenol-chloroform extraction. Anal. Biochem. 162, 156-159.

Doherty P., Seaton P., Flanigan T. P., and Walsh F. S. (1988) Factors controlling the expression of the NGF receptor in $\mathrm{PCl} 2$ cells. Neurosci. Lett. 92, 222-227.

Dussault J. H. and Rouel J. (1987) Thyroid hormones and brain development. Annu. Rev. Physiol. 49, 321-334.

García-Villalba P., Au-Fliegner M., Samuels H., and Aranda A. (1993) Interaction of thyroid hormone and retinoic acid receptors on the regulation of the rat growth hormone gene promoter. Biochem. Biophys. Res. Commun. 191, 580-586.

Gizang-Ginsberg E. and Ziff E. B. (1994) Fos family members successively occupy the tyrosine hydroxylase gene AP-1 site after nerve growth factor or epidermal growth factor stimulation and can repress transcription. Mol. Endocrinol. 8, 249-262.

Greene L. A. and Tischler A. (1976) Establishment of a noradrenergic clonal line of rat adrenal pheochromocytoma cells which respond to nerve growth factor. Proc. Natl. Acad. Sci. USA 73, $2424-2428$.

Greene L. A. and Tischler A. (1982) PC12 pheochromocytoma cultures in neurobiological research. Adv. Cell. Neurobiol. 3, $373-414$.

Grima B., Lamouroux A., Blanot F., Faucon Biguet N., and Mallet J. ( 1985 ) Complete coding sequence of rat tyrosine hydroxylase mRNA. Proc. Natl. Acad. Sci. USA 82, 617-621.

Guiguère V. (1994) Retinoic acid receptors and cellular retinoid binding proteins: complex interplay in retinoid signaling. Endocr. Rev. 15, 61-79.

Halegoua S., Armstrong R. B., and Kremer N. E. (1991) Dissecting the mode of action of a neuronal growth factor. Curr. Top. Microbiol. Immunol. 165, 119-170.

Hantzopoulos P. A., Suri C., Glass D. J., Goldfarb M. P., and Yancopoulos G. D. (1994) The low affinity NGF receptor, p75, can collaborate with each of the Trks to potentiate functional responses to the neurotrophins. Neuron 13, 187-201.

Haussler M., Sidell N., Kelly M., Donaldson C., Altman A., and Mangelsdorf D. (1983) Specific high-affinity binding and biological action of retinoic acid in human neuroblastoma cell lines. Proc. Natl. Acad. Sci. USA 80, 5525-5529.

Hempstead B. L., Martin-Zanca D., Kaplan D. R., Parada L. F., and Chao M. V. (1991) High-affinity NGF binding requires coexpression of the trk proto-oncogene and the low-affinity NGF receptor. Nature 350, 678-683

Johnson D., Lanahan A., Buck C. R., Sehgl A., Morgan C., Mercer E., Bothwell M., and Chao M. (1986) Expression and structure of the human NGF receptor. Cell 47, 545-554.

Jones-Villeneuve E. M. V., McBurney M. W., Rogers K. A., and Kalnins V. I. (1982) Retinoic acid induces embryonal carcinoma cells to differentiate into neurons and glial cells. $J$. Cell Biol. 94, 253-263.

Kaplan D. R., Hempstead B. L., Martin-Zanca D., Chao M. V., and Parada L. F. ( 1991 ) The trk proto-oncogene product: a signal transducing receptor for nerve growth factor. Science 252, 554558.

Kaplan D. R., Matsumoto K., Lucarelli E., and Thiele C. J. ( 1993 ) Induction of TrkB by retinoic acid mediates biological responsiveness to BDNF and differentiation of human neuroblastoma cells. Neuron 11, 321-331.

Kazlauskas A. (1994) Receptor tyrosine kinases and their targets. Curr. Opin. Genet. Dev. 4, 5-14.
Klein R., Jing S., Nanduri V., O'Rourke E., and Barbacid M. (1991) The trk proto-oncogene encodes a receptor for nerve growth factor. Cell 65, 189-197.

Lazar M. A. (1993) Thyroid hormone receptors: multiple forms multiple possibilities. Endocr. Rev. 14, 194-203.

Leonard D. G. B., Ziff E. B., and Greene L. A. ( 1987) Identification and characterization of mRNAs regulated by nerve growth factor in PC12 cells. Mol. Cell. Biol. 7, 3156-3167.

Levi-Montalcini R. (1987) The nerve growth factor 35 years later. Science 237, 1154-1162.

Lewis E. J., Tank W., Weiner N., and Chikaraishi D. M. (1983) Regulation of tyrosine hydroxylase mRNA by glucocorticoid and cyclic AMP in a rat pheochromocytoma cell line. J. Biol. Chem. 258, 14632-14637.

Loeb D. M., Maragos J., Martin-Zanca D., Chao M. V., Parada L. F., and Greene L. A. (1991) The trk proto-oncogene rescues NGF responsiveness in mutant NGF-non responsive PC1 2 cell lines. Cell 66, 961-966.

Mangelsdorf D. J., Ong E. S., Dyck J. A., and Evans R. M. (1990) Nuclear receptor that identifies a novel retinoic acid response pathway. Nature 345, 224-229.

Miller F. D., Mathew T. C., and Toma J. G. (1991) Regulation of nerve growth factor receptor gene expression by nerve growth factor in the developing peripheral nervous system. J. Cell Biol. $112,303-312$.

Muñoz A., Wrighton C., Seliger B., Bernal J., and Beug H. (1993) Thyroid hormone receptor/c-erbA: control of commitment and differentiation in the neuronal/chromaffin progenitor line PC12. J. Cell Biol. 121, 423-438.

Radeke M. J., Misko T. P., Hsu C., Herzenberg L. A., and Shooter E. M. (1987) Gene transfer and molecular cloning of the rat nerve growth factor receptor. Nature 325, 593-597.

Rodriguez-Tebar A. and Rohrer H. (1991) Retinoic acid induces NGF-dependent survival response and high affinity NGF receptors in immature chick sympathetic neurons. Development 112 , $813-820$.

Sap J., Muñoz A., Damm K., Goldberg Y., Ghysdael J., Leutz A., Beug H., and Vennström B. (1986) The c-erbA protein is a high-affinity receptor for thyroid hormone. Nature 324, 635640.

Scheibe R. J. and Wagner J. A. (1992) Retinoic acid regulates both expression of the nerve growth factor receptor and sensitivity to nerve growth factor. J. Biol. Chem. 267, 17611-17616.

Scheibe R. J., Ginty D. D., and Wagner J. A. (1991) Retinoic acid stimulates the differentiation of PCI 2 cells that are deficient in c-AMP dependent protein kinase. J. Cell Biol. 113, 1173-1182.

Strickland S., Smith K. K., and Marotti K. R. (1980) Hormonal induction of differentiation in teratocarcinoma stem cells: generation of parietal endoderm by retinoic acid and dibutyryl cAMP. Cell 21, 347-355.

Tischler A. S., Riseberg J. C., Hardenbrook M. A., and Cherington V. (1993) Nerve growth factor is a potent inducer of proliferation and neuronal differentiation for rat chromaffin cells in vitro. J. Neurosci. 13, 1533-1542.

Togari A., Baker D., Dickens G., and Guroff G. ( 1983 ) The neuritepromoting effect of fibroblast growth factor on $\mathrm{PCl} 2$ cells. Biochem. Biophys. Res. Commun. 114, 1189-1193.

Umesono K., Guiguère V., Glass C. K., Rosenfeld M. G., and Evans R. M. (1988) Retinoic acid and thyroid hormone induce gene expression through a common responsive element. Nature 336, $262-265$.

Umesono K., Murakami K. K., Thompson C. C., and Evans R. M. (1991) Direct repeats as selective response elements for the thyroid hormone, retinoic acid and vitamin D3 receptors. Cell 65, 1255-1266.

Vivanco-Ruiz M. M., Bugge T. H., Hirschmann P., and Stunnenberg T. H. (1991) Functional characterization of a natural retinoic acid responsive element. EMBO J. 10, 3829-3838.

Yakovlev A. G., De Bernardi M. A., Fabrazzo M., Brooker G., Costa E., and Mocchetti I. (1990) Regulation of nerve growth factor receptor mRNA content by dexamethasone, in vitro and in vivo studies. Neurosci. Lett. 116, 216-220. 